Corrigendum

\title{
Corrigendum to "Fish Collagen Promotes the Expression of Genes Related to Osteoblastic Activity"
}

\author{
Mark Luigi Fabian Capati, Ayako Nakazono, \\ Kohei Yamamoto, Kouji Sugimoto, Kajiro Yanagiguchi, \\ Shizuka Yamada, and Yoshihiko Hayashi
}

Department of Cariology, Nagasaki University Graduate School of Biomedical Sciences, Nagasaki 852-8588, Japan

Correspondence should be addressed to Yoshihiko Hayashi; hayashi@nagasaki-u.ac.jp

Received 26 October 2017; Accepted 29 October 2017; Published 22 November 2017

Copyright (C) 2017 Mark Luigi Fabian Capati et al. This is an open access article distributed under the Creative Commons Attribution License, which permits unrestricted use, distribution, and reproduction in any medium, provided the original work is properly cited.

In the article titled "Fish Collagen Promotes the Expression of Genes Related to Osteoblastic Activity" [1], there were errors, which should be corrected as follows:

(i) The term "TCA" should be corrected to "TAC" throughout the article.

(ii) In the sixth row of Table 1, "Chordin-like 1 (Chrd1)" should be corrected to "Chordin-like 1 (Chrdl1)." The corrected table is shown below.

(iii) In Figure 1, "Pgfr" should be corrected to "Fgfr3," and "Chrdl" should be corrected to "Chrdll." The corrected figure is shown below.

(iv) In the Discussion, "In the present experiment, the function of MC3T3-E1 cells was accelerated after three-day culture in FC-positive or BGP-positive group, which was confirmed by the increase of the expression of calcification-related genes, except OCN," should be corrected to "In the present experiment, the function of MC3T3-E1 cells was accelerated after three-day culture in FC-positive or BGP-positive group, which was confirmed by the increase of the expression of calcification-related genes, except OPN." 
TABLE 1: Primers designed for RT-PCR analyses of genes related to cell proliferation and differentiation.

\begin{tabular}{|c|c|}
\hline Gene name & Oligonucleotides \\
\hline \multirow{2}{*}{ Matrix metallopeptidase 13 (Mmp13) } & Forward: AGGCCTTCAGAAAAGCCTTC \\
\hline & Reverse: GGTCCTTGGAGTGATCCAGA \\
\hline \multirow{2}{*}{ Wnt inhibitory factor 1 (Wif1) } & Forward: GAGTGTCCGGATGGGTTCTA \\
\hline & Reverse: TGGTTGAGCAGTTTGCTTTG \\
\hline \multirow{2}{*}{ Receptor activity modifying protein 1 (Rampl) } & Forward: GCGGTATCCTCCTGAAAACA \\
\hline & Reverse: CAGTCCTCCAGTTGGACCAT \\
\hline \multirow{2}{*}{ SMAD family member 6 (Smad6) } & Forward: ACGGTGACCTGCTGTCTCTT \\
\hline & Reverse: AGCGAGTACGTGACCGTCTT \\
\hline \multirow{2}{*}{ Platelet-derived growth factor, D polypeptide (Pdgfd) } & Forward: TCAGCTGTGTGCTCAACAAA \\
\hline & Reverse: ATTGGGCCTGGCTTACTTCT \\
\hline \multirow{2}{*}{ Chordin-like 1 (Chrdll) } & Forward: TGGTCTTTGCTTTCCCATGT \\
\hline & Reverse: CCCAGGTGTTCTCTGAAAGC \\
\hline \multirow{2}{*}{ Septin 4 (Sept4) } & Forward: TTCAGGTCCAAAAGCCAGTT \\
\hline & Reverse: TGACTTCCCTATCCCTGCTG \\
\hline \multirow{2}{*}{ Fibroblast growth factor receptor 3 (Fgfr3) } & Forward: ACAAGGACCGTACTGCCAAG \\
\hline & Reverse: ACCTGGTAGGCACAGGACAC \\
\hline \multirow{2}{*}{ Lumican (Lum) } & Forward: TTCTCTCTTGCCTTGGCATT \\
\hline & Reverse: CACTGCAGGTCTGTGACGTT \\
\hline \multirow{2}{*}{ Vitamin D receptor (Vdr) } & Forward: CGGAAATGGGTACCAAAATG \\
\hline & Reverse: CACGTAGCAAGCGCTATGAA \\
\hline \multirow{2}{*}{ Ribosomal protein S17 (rpS17) } & Forward: GCATATCATGCAACGCTTTC \\
\hline & Reverse: GGAGCTTCAGCATCTCСTTG \\
\hline
\end{tabular}

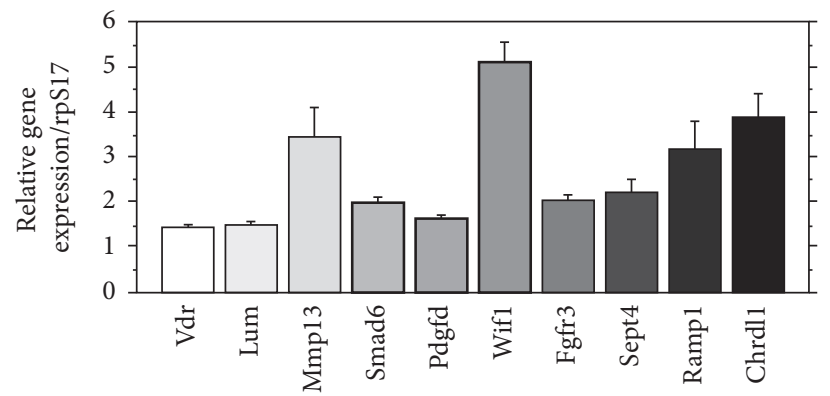

FIGURE 1: RT-PCR for 10 genes in relation to cell proliferation and differentiation. Each bar indicates the SD of triplicate samples.

\section{References}

[1] M. L. F. Capati, A. Nakazono, K. Yamamoto et al., "Fish collagen promotes the expression of genes related to osteoblastic activity," International Journal of Polymer Science, vol. 2016, Article ID 5785819, 7 pages, 2016. 

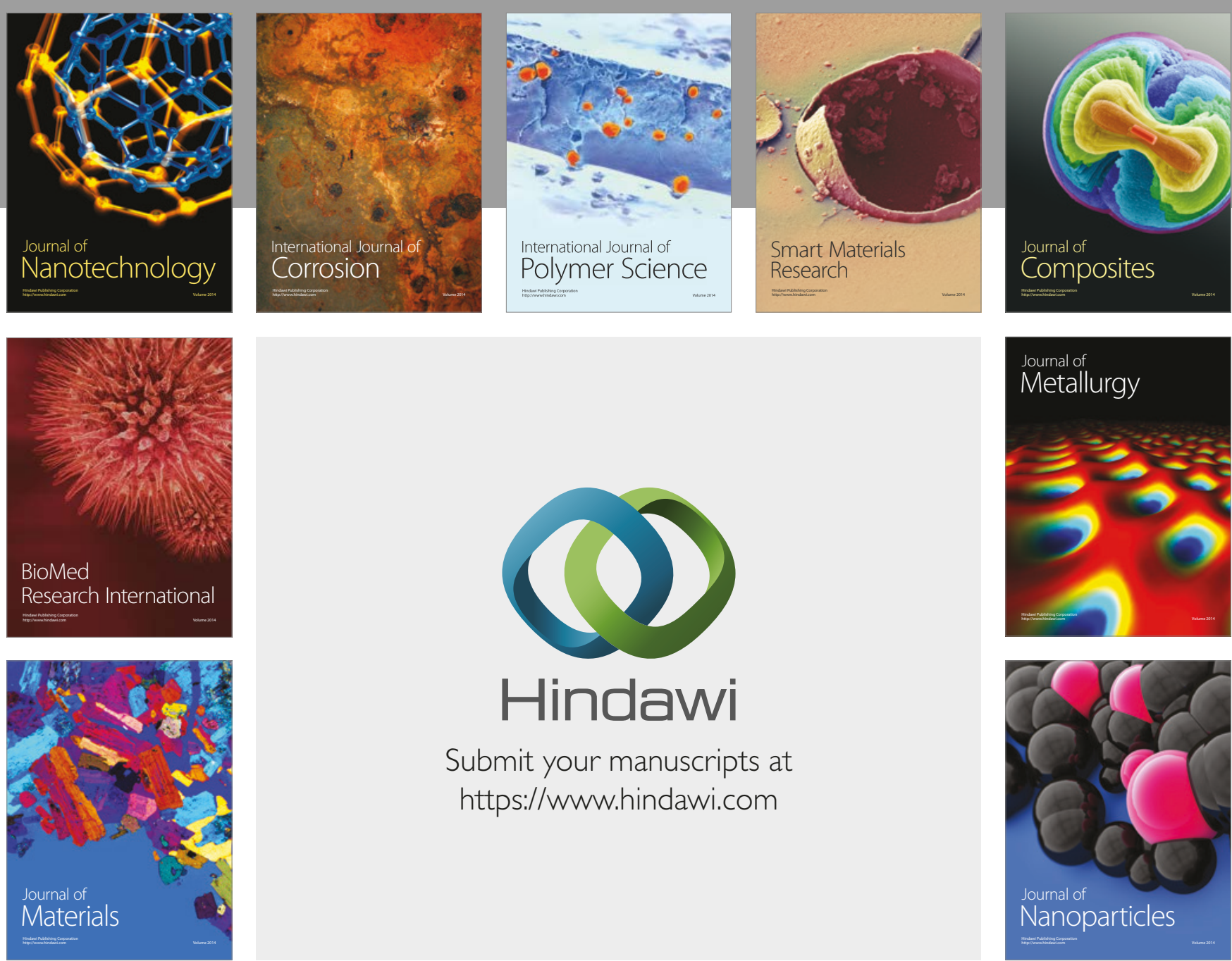

\section{Hindawi}

Submit your manuscripts at

https://www.hindawi.com
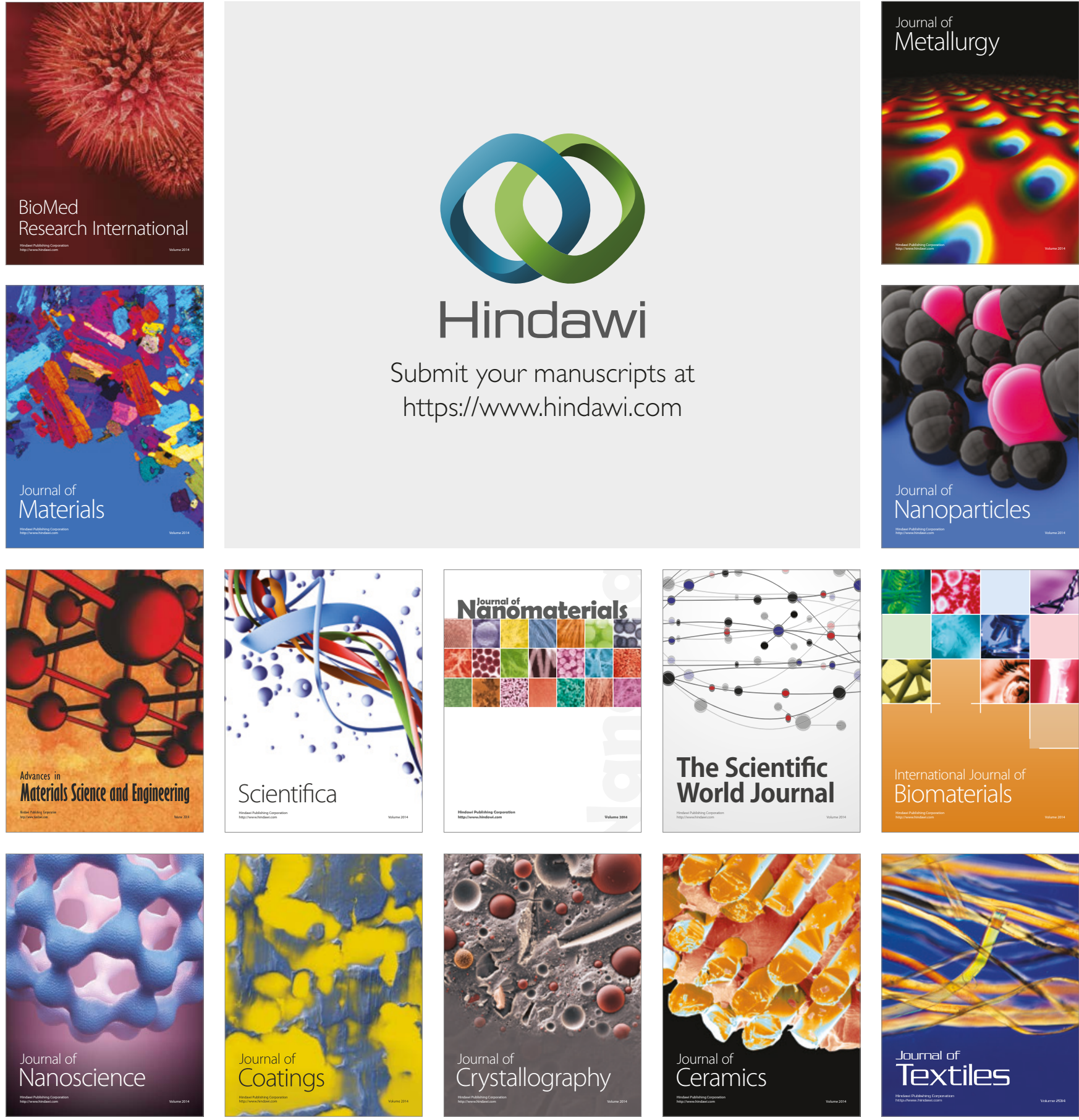

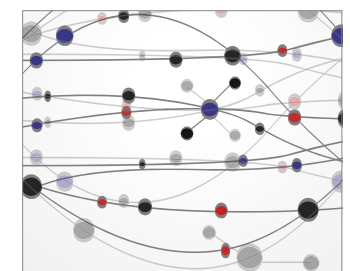

The Scientific World Journal
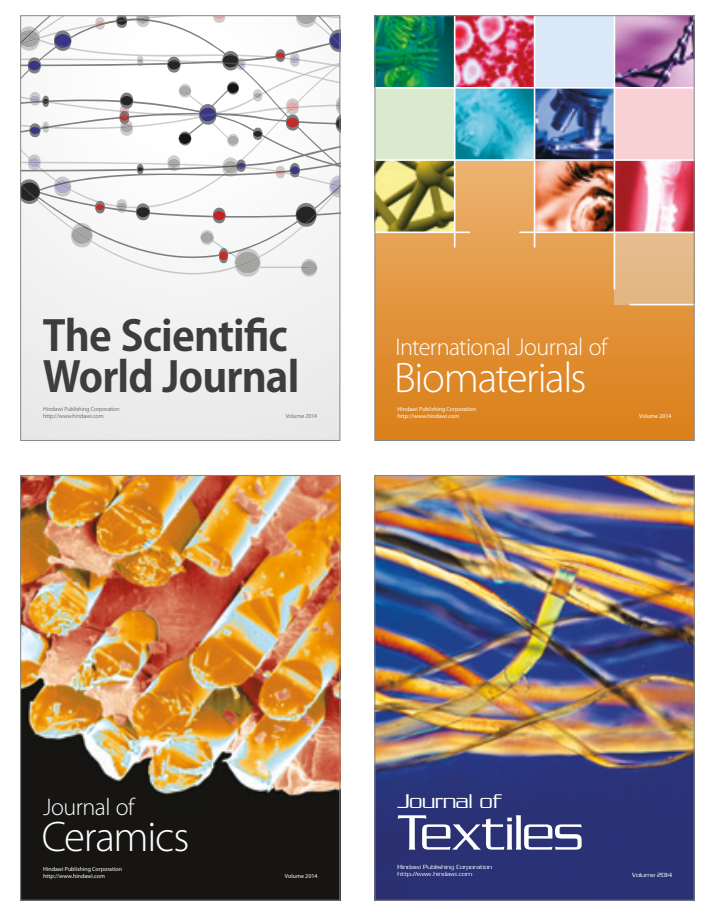